\title{
Effectiveness of Botulinum Toxin in Managing Temporomandibular Disorders: A Systematic Review
}

Abdullah Al-Hussain ${ }^{*}$, Eman Almahozi ${ }^{2}$, Khulood Bakhsh ${ }^{3}$, Ruba Jayar ${ }^{4}$, Rahmah Aljohani ${ }^{5}$, Ahmed Alzahrani ${ }^{6}$, Mohammed Al Khars ${ }^{7}$, Ruba Alkhalil ${ }^{8}$, Heba Ismail ${ }^{9}$, Maryam AlRamadhan ${ }^{10}$, Mohammed Althobaiti ${ }^{11}$

${ }^{1}$ Department of Advanced General Dentistry, Ministry of National Guards Health Affairs, Riyadh, Saudi Arabia.

${ }^{2}$ College of Dentistry, Ajman University of Science and Technology, Ajman, UAE

${ }^{3}$ Department of Restorative Dentistry, King Fahad Hospital, Jeddah, Saudi Arabia

${ }^{4}$ Primary Health Care, Ministry of Health, Medina, Saudi Arabia

${ }^{5}$ College of Dentistry, Jordan University of Science and Technology, Irbid, Jordan

${ }^{6}$ College of Dentistry, King Khalid University, Abha, Saudi Arabia

${ }^{7}$ College of Dentistry, King Faisal University, Al Ahsaa, Saudi Arabia

${ }^{8}$ Primary Health Care, Ministry of Health, Unizah, Saudi Arabia

${ }^{9}$ College of Dentistry, Ibn Sina National College, Jeddah, Saudi Arabia

${ }^{10}$ College of Dentistry, Batterjee Medical College, Jeddah, Saudi Arabia

${ }^{11}$ Primary Health Care, Ministry of Health, Mecca, Saudi Arabia

Correspondence should be addressed to Abdullah Al-Hussain, Department of Advanced General Dentistry, Ministry of National Guards Health Affiar, Riyadh, Saudi Arabia. Email: dr.abdullahalhussain@gmail.com

Received 9 March 2021; Revised 25 March 2021; Accepted 9 April 2021; Published 13 April 2021

Copyright (c) 2021 Al-Hussain et al. This is an open access article distributed under the Creative Commons Attribution License, which permits unrestricted use, distribution, and reproduction in any medium, provided the original work is properly cited.

\begin{abstract}
Botulinum toxin (BTX) has been widely used in the management of Temporomandibular Disorders (TMD) due to its analgesic and relaxing abilities, and its relatively fast disposal of poor compliance. In this systematic review, we aim to discuss the effectiveness of BTX in the management of TMD, including its effect on pain, maximum mouth opening, and adverse effects. A systematic electronic database search was conducted in seven databases for relevant studies published prior to 7 July 2020. Generally, pain relief improved over time in most of the included studies. Both slight and significant improvements in mouth opening following BTX injection were observed. No serious adverse effects or complications were reported by the included studies. Adverse effects reported were headaches, weakness, increased pain, flu-like symptoms, chewing discomfort, and unilateral paralysis of the zygomaticus major muscle. However, adverse effects caused by BTX local infusion may be dose dependant, and this aspect should be considered in future investigations. This study demonstrates that it is difficult to determine the effect of BTX on TMD patients, and it is essential that more research is conducted in this field with proper populations and fewer limitations. However, we can conclude that the administration of BTX is almost free of severe complications and may only cause minimal adverse effects.
\end{abstract}

Keywords: Botulinum toxin; Temporomandibular disorders; Effectiveness 


\section{Introduction}

Temporomandibular Disorders (TMD) have been defined as a group of musculoskeletal or neuromuscular conditions that are related to the temporomandibular joint, the muscles of mastication and the surrounding tissues. It has been identified as the third most common cause of pain after headaches and back pain, and the most common cause of pain in the orofacial region (1, 2). Different assessment approaches regarding TMD have not been widely reported as different classifications are often used to identify the disease, which involves a wide range of disorders. However, a 10 to $30 \%$ increase in prevalence rate of TMD has been identified (3-7). Additionally, few patients suffering from TMD seek medical attention (8).

The clinical presentation of the disorder includes a variety of symptoms and signs including neck pain, orofacial pain involving the jaw, decreased jaw excursion, tinnitus, crepitus, trismus, headache, earache and periorbital pain $(9,10)$. Various cause factors have been identified for TMD. They include inherited and psychological features and parafunctional habits including bruxism, trauma and occlusion (11-15). The diagnosis of TMD is complicated as there are various factors involved in its etiology. As such, various clinical signs regarding TMD should be investigated. Bruxism, known simply as the unconscious clenching of the jaw, is one of the most common contributing factors to TMD (15). However, patients suffering from TMD may also present with other similar myogenous characteristics that are also widely found when diagnosing and classifying TMD $(11,16,17)$.

A history of aural fullness, tinnitus and otalgia should be considered due to the double innervation of the Temporomandibular Joint (TMJ) and ear muscles by the trigeminal nerve (18). Jaw-related medical events including trauma, malocclusion and a history of orthodontic treatment should also be given consideration. Imaging approaches that include Orthopantomograms (OPG) and Magnetic Resonance Imaging (MRI) have been used to assess the integrity of joint movement, dentition and the presence of underlying rheumatological disorders (19).

The initial treatment of TMD avoids further exposure to the aforementioned risk and aetiological factors, and provides joint relief via proper diet and physiotherapy, warm compresses and local analgesia. Additionally, various management approaches have been described for the management of TMD, including pharmacological treatment and surgical procedures $(20,21)$. Botulinum Toxin (BTX), which is a potent neurotoxin released by Clostridium Botulinum, has been used as adjuvant therapy for managing head and neck pain $(22,23)$. It has also been studied as the primary treatment for cervical dystonia and other muscular disorders (24). From a cosmetic perspective, BTX has also been reported to result in significant enhancements without severe adverse effects (25). BTX is administered via intramuscular injection, as the poison acts by acetylcholine release blockage from the presynaptic nerve endings which results in the relaxation of the muscles and the relief of neurogenic pain (26). Other mechanisms include a reduced release of inflammatory mediators and controversial central action by exclusively decreasing the sensitization for chronic pain $(27,28)$. Consequently, BTX has been widely used in the management of TMD due to its analgesic and relaxing abilities and its relatively fast action disposal of poor compliance. In this systematic review, we aim to discuss the effectiveness of BTX in the management of TMD including its effect on pain, maximum mouth opening and its adverse effects.

\section{Methods}

\section{Search strategy and study selection}

The study's methodology followed the accepted recommendations of the Preferred Reporting Items for Systematic Reviews and Meta-Analyses (PRISMA) checklist (29). A systematic electronic database search was undertaken for relevant studies published prior to 1 March 2021 in seven databases including Google Scholar, Scopus, Web of Science, PubMed, Cochrane Central Register of Controlled Trials (CENTRAL), Embase, and CINAHL using keywords and medical subject $(\mathrm{MeSH})$ terms. In databases that do not support MeSH terms combinations of all possible terms were used. Additionally, a manual search was undertaken of references from the included articles by searching for primary studies that had cited our identified papers and scanning references of the relevant papers in PubMed and Google Scholar to avoid missing any relevant publications (30). We have included all original relevant studies that discuss the effectiveness of BTX in managing emporomandibular disorders. Papers were excluded if they featured one of the following exclusion 


\section{Journal of Healthcare Sciences}

criteria: pilot studies, duplicate records, incomplete reports or data that could not be reliably extracted, abstract-only articles, theses, books and conference papers. Title and abstract screening were undertaken independently by four reviewers. Then, three further independent reviewers performed a full-text screening to ensure the inclusion of relevant papers. Any disagreement was resolved via discussion and by referring to the senior author when necessary.

\section{Data extraction}

Four authors developed the data extraction sheet using Microsoft Excel software. Data extraction was undertaken by three independent reviewers using the excel sheet. Two independent reviewers performed data checking to ensure the accuracy of the extracted data. All disagreements and discrepancies were resolved by discussion and consultation with the senior author when necessary.

Table 1. Characteristics and quality of the included studies

\begin{tabular}{|c|c|c|c|c|c|c|c|c|}
\hline $\begin{array}{l}\text { Autho } \\
\text { r, year }\end{array}$ & Country & Design & $\begin{array}{l}\text { Sampl } \\
\text { e size }\end{array}$ & $\underset{\%}{\text { Male }}$ & $\begin{array}{l}\text { Age } \\
\text { mean } \\
(\mathrm{SD})\end{array}$ & Aim & Conclusion & $\begin{array}{l}\text { Overall } \\
\text { Quality }\end{array}$ \\
\hline $\begin{array}{l}\text { Altaweel, } \\
\text { 2019(33) }\end{array}$ & Egypt & $\begin{array}{l}\text { Cohort } \\
\text { study }\end{array}$ & 14 & 28.57 & $\begin{array}{c}23.28 \\
( \pm 2.01)\end{array}$ & $\begin{array}{l}\text { To compare between extra-oral and intra-oral } \\
\text { approach for BTX-A injection into the LPM } \\
\text { in patients suffering from ADDWR }\end{array}$ & $\begin{array}{l}\text { The BTX-A injection into LPM is a simple technique } \\
\text { that can be used with high success and low complication } \\
\text { rate for treatment of ADDWR. The intraoral approach } \\
\text { was superior to the extraoral concerning patient } \\
\text { convenience and injection duration with no statistical } \\
\text { difference regarding other clinical outcomes }\end{array}$ & Fair \\
\hline $\begin{array}{l}\text { Batifol, } \\
\text { 2018(34) }\end{array}$ & France & $\begin{array}{l}\text { Cohort } \\
\text { study }\end{array}$ & 77 & 32.47 & $\begin{array}{l}46 \text { (range } \\
21 \text { to } 78 \text { ) }\end{array}$ & $\begin{array}{l}\text { To evaluate the effectiveness of such } \\
\text { injections on severe, refractory temporo- } \\
\text { mandibular joint pain. This was a } \\
\text { retrospective study }\end{array}$ & $\begin{array}{l}\text { Intra-articular injection of Botulinum toxin is a safe and } \\
\text { effective treatment for severe, refractory temporo- } \\
\text { mandibular joint pain, avoiding surgery. }\end{array}$ & Fair \\
\hline $\begin{array}{l}\text { Calis, } \\
\text { 2019(35) }\end{array}$ & Turkey & $\begin{array}{l}\text { Cohort } \\
\text { study }\end{array}$ & 9 & 44.44 & 33.67 & $\begin{array}{l}\text { To investigate the efficacy of botulinum toxin } \\
\text { injection in the treatment of muscular TMD }\end{array}$ & $\begin{array}{c}\text { Botulinum toxin injection for the treatment of muscular } \\
\text { temporomandibular joint disorder is a viable treatment } \\
\text { option in the case of patients who do not respond to } \\
\text { conservative treatment methods }\end{array}$ & Good \\
\hline $\begin{array}{l}\text { Ernberg, } \\
\text { 2011(36) }\end{array}$ & Sweden & RCT & 21 & 9.5 & $38( \pm 12)$ & $\begin{array}{c}\text { To investigate the BTX A in patients with } \\
\text { persistent TMD }\end{array}$ & $\begin{array}{l}\text { Results do not indicate a clinical relevant effect of BTX- } \\
\text { A in patients with persistent myofascial TMD pain }\end{array}$ & Fair \\
\hline $\begin{array}{l}\text { Guarda- } \\
\text { Nardini, } \\
\text { 2008(37) }\end{array}$ & Italy & RCT & 20 & 50 & $\begin{array}{l}\text { range } 25- \\
\quad 45\end{array}$ & $\begin{array}{l}\text { To assess the efficacy of type A botulinum } \\
\text { toxin (Botox, Allergan, Inc. Irvine, CA) to } \\
\text { treat myofascial pain symptoms and to reduce } \\
\text { muscle hyperactivity in bruxers }\end{array}$ & $\begin{array}{c}\text { Results support the efficacy of BTX-A to reduce } \\
\text { myofascial pain symptoms in bruxers, and provided } \\
\text { pilot data which need to be confirmed by further } \\
\text { research using larger samples }\end{array}$ & Fair \\
\hline $\begin{array}{l}\text { Guarda- } \\
\text { Nardini, } \\
\text { 2012(38) }\end{array}$ & Italy & RCT & 30 & 26.7 & $\begin{array}{c}45.45 \\
( \pm 14.04)\end{array}$ & $\begin{array}{l}\text { To compare the short-term effectiveness of } \\
\text { botulinum toxin injections and physiatric } \\
\text { treatment provided by means of fascial } \\
\text { manipulation techniques in the management } \\
\text { of myofascial pain of jaw muscles } \\
\end{array}$ & $\begin{array}{l}\text { Findings from the present investigation are in line with } \\
\text { literature data supporting the effectiveness of a wide } \\
\text { spectrum of conservative treatment approaches to } \\
\text { myofascial pain of the jaw muscles. }\end{array}$ & Good \\
\hline $\begin{array}{l}\text { Kurtoglu, } \\
2008(39)\end{array}$ & Turkey & RCT & 24 & 16.7 & $\begin{array}{c}26.5 \\
( \pm 9.88)\end{array}$ & $\begin{array}{l}\text { To evaluate the effects of BTX A in the } \\
\text { treatment of patients who have myofascial } \\
\text { pain with or without functional disc } \\
\text { displacement. }\end{array}$ & $\begin{array}{l}\text { The injection of BTX A decreases the muscle action } \\
\text { potential in } 14 \text { days. The patients also show } \\
\text { improvement in pain and psychological status }\end{array}$ & Fair \\
\hline $\begin{array}{l}\text { Nixdorf, } \\
\text { 2002(40) }\end{array}$ & Canada & RCT & 15 & 0 & $\begin{array}{c}3318-45 \\
\text { (range) }\end{array}$ & $\begin{array}{l}\text { to determine whether BTX A was efficacious } \\
\text { for the treatment of chronic moderate to } \\
\text { severe jaw muscle pain in females }\end{array}$ & $\begin{array}{l}\text { The results do not support the use of BTX-A in the } \\
\text { treatment of moderate to severe jaw muscle pain in this } \\
\text { patient population }\end{array}$ & Fair \\
\hline $\begin{array}{c}\text { Patel, } \\
\text { 2017(41) }\end{array}$ & USA & RCT & 19 & NA & NA & $\begin{array}{l}\text { To examine the effectiveness and safety of } \\
\text { IncobotulinumtoxinA in relieving the } \\
\text { subject's muscle spasm and pain associated } \\
\text { with TMD }\end{array}$ & $\begin{array}{l}\text { We demonstrate utility of IncobotulinumtoxinA in } \\
\text { treating patients with TMD with pain despite pain } \\
\text { medication usage and other conventional treatments }\end{array}$ & Fair \\
\hline $\begin{array}{l}\text { von } \\
\text { Lindern, } \\
\text { 2003(42) }\end{array}$ & Germany & RCT & 90 & NA & NA & $\begin{array}{c}\text { To assess whether the targeted reduction of } \\
\text { masticatory muscular hyperactivity by local } \\
\text { injection treatment with botulinum toxin type } \\
\text { A can improve facial pain headache } \\
\text { symptoms in the event that other treatment } \\
\text { methods prove ineffective }\end{array}$ & $\begin{array}{l}\text { The local injection of BTX A constitutes an innovative } \\
\text { and adequately efficient treatment method for chronic } \\
\text { facial pain associated with hyperactivity of the } \\
\text { masticatory muscles. An improvement in the painful } \\
\text { symptoms can be expected in up to } 90 \% \text { of patients who } \\
\text { do not respond to conservative treatment methods. }\end{array}$ & Bad \\
\hline $\begin{array}{l}\text { Yoshida, } \\
\text { 2018(43) }\end{array}$ & Japan & $\begin{array}{l}\text { Cohort } \\
\text { study }\end{array}$ & 32 & 40.63 & $\begin{array}{c}62.3 \\
( \pm 24.0)\end{array}$ & $\begin{array}{l}\text { To compare treatment outcomes following } \\
\text { intramuscular injection of BoNT in patients } \\
\text { with recurrent temporomandibular joint } \\
\text { dislocation, with and without muscle } \\
\text { hyperactivity due to neurological diseases }\end{array}$ & $\begin{array}{l}\text { No significant immediate or delayed complications } \\
\text { occurred. Thus, intramuscular injection of BoNT into } \\
\text { the lateral pterygoid muscle is an effective and safe } \\
\text { treatment for habitual temporomandibular joint } \\
\text { dislocation. More injections are required in cases of } \\
\text { neurogenic temporomandibular joint dislocation than in } \\
\text { those of habitual dislocation without muscle } \\
\text { hyperactivity }\end{array}$ & Bad \\
\hline
\end{tabular}

ADDWR: anterior disc displacement with reduction, BoNT: botulinum neurotoxin, BTX-A: botulinum toxin type A, RCT: randomized controlled trials, SD: standard deviation, TMD: temporomandibular disorders 
Journal of Healthcare Sciences

\section{Quality assessment}

Five independent reviewers evaluated the risk of bias in the included studies. The National Institutes of Health (NIH) quality assessment tools were used to determine the quality of included studies, in reference to their study design (31). Quality assessment of each study was obtained via a scoring system that comprised of 14 questions. The criteria was judged as follows; a score of 13 to 14 was good, 9 to 12 was fair, and studies scoring below 9 were considered to be poor quality (32). Any discrepancies between the reviewers were solved via discussion.

\section{Results}

\section{Search results}

Initially, a total of 1,161 records were extraced; of which 308 duplicates were removed, resulting in 853 papers for title and abstract screening. Following the first screening, 59 articles were selected for full-text screening.
After the exclusion of an additional 48 records, 11 studies were included the final systematic review. Manual search efforts did not find any additional relevant papers (Figure 1).

\section{Characteristics and quality of the included}

\section{studies.}

The sample size of the included studies ranged from 9 to 90 individuals, with a male percentage ranging from 9.5 to $50 \%$. The patient mean ages were simialrly wideranging, from 23.28 to 62.3 years. The characteristics of the studies are summarized in Table 1. Seven of the included studies were assessed using the NIH tool for randomized controlled trials and the remaining four were assessed using cohort and cross-sectional tools. Overall, the group was comprised of seven studies of fair quality, two of good quality, and two of poor quality. Assessor blinding, lack of follow-up and control for co-founders were the most defective domains (Table 1).

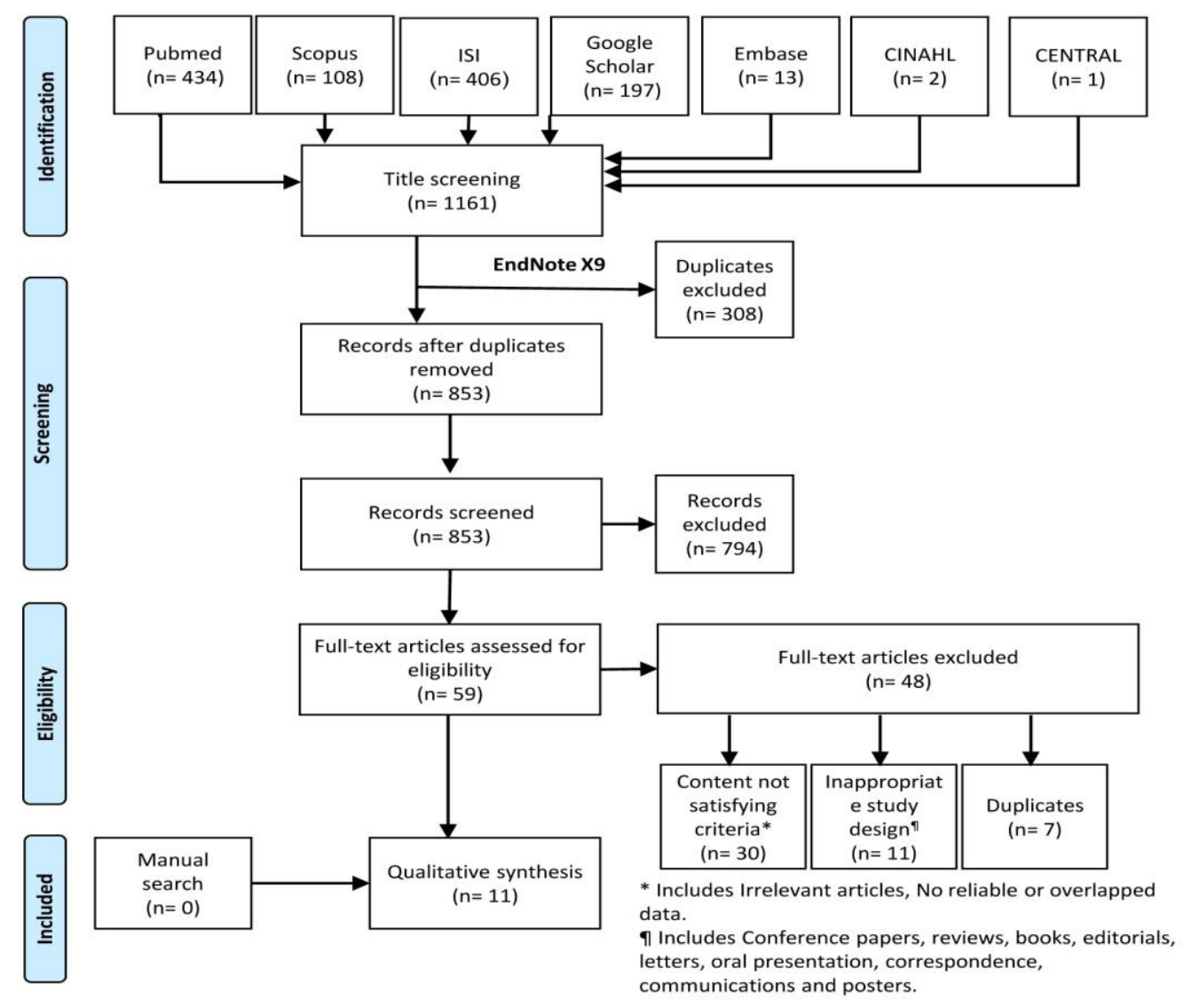

Figure 1: PRISMA flowchart summarizing the search process in this study 


\section{Discussion}

BTX is a $150 \mathrm{kDa}$ exotoxin with seven serotypes ranging from A to $G$ with Serotype A (BTX-A) the most available serotype $(23,33)$. Its mechanism of action is temporary lasting from three to six months (22). It has been widely used to manage head and neck pain, including migraine headaches, sialorrhoea, post-herpetic neuralgia, masseteric hypertrophy, hemifacial spasm and frey syndrome (34). Despite being approved for several disorders such as chronic migraine, bladder overcapacity and cervical dystonia (34), the use of BTX in TMD has not yet been verified due to the variety of reported results. In 2002, Schwartz et al. (35) were the first to report BTX beneficial properties for TMD patients after applying it topically to the affected structure. Many subsequent studies reported similar findings, but with different dosages and BTX application techniques. Aside from reducing the release of chemical transmitters at the nerve endings, BTX also has a direct analgesic effect on nociceptors via inhibition of substance $\mathrm{P}$, calcitonin, glutamine and gene regulated peptide (27) which decreases pain in the neighboring groups of muscles within four days of injection (15). Formulations of BTX in these studies include abobotulinumtoxin A (Dysport, Ipsen), incobotulinumtoxin A (Xeomin, Merz Pharmaceuticals), onabotulinumtoxin A (Botox, Allergan), and rimabotulinumtoxinB (Myobloc, Solstice Neurosciences). To reduce discomfort after a BTX injection, our identified studies diluted the injection before introducing it to their patients. However, Gassner et al. reported that local anesthesia can also be used to utilize the complete potency of BTX (36). Among the included studies, nine $(15,22, \quad 37-43)$ used onabotulinumtoxinA (Botox, Allergan) whilst GuardaNardini et al. (44), and Patel et al. (45) used abobotulinumtoxin A (Dysport, Ipsen), and incobotulinumtoxin A (Xeomin, Merz Pharmaceuticals), respectively. However, studies that identify the effects of one formulation over another have not been published, and we could therefore not determine which is the best and most effective formula. Further investigations should compare between different formulations (46).

Despite the importance of using defined criteria for diagnosing TMD patients as reported by Thambar et al. (47), only seven studies $(22,37,39,40,44,45,48)$ used the Research Diagnostic Criteria for Temporomandibular Disorders (RDC/TMD) (17), while the remaining four used their own diagnostic criteria $(38,41-43)$. As for pain evaluation, almost all studies used a numeric Visual Analog Scale (VAS), and only two utilized behavioral evaluations of their patients $(39,43)$. Despite its prevalence, VAS assessment is not the best method for pain evaluation as results are variable and dependent on the nature of data collection and frequency of the patients' recalls. Conversely, Conti et al. (49) compared a behavior scale against the VAS to assess reliability and validity and determined that the best way to assess pain was via a numerical scale.

Variations in the injected muscle of mastication and dosages of BTX have been noticed. From all of our included studies, eight $(15,22,39-42,44,45)$ injected patients in the masseter muscle, and seven $(15,39-42$, $44,45)$ injected patients in both the masseter and temporalis muscle. Only Patel et al. (45) injected in the masseter, temporalis, and lateral pterygoid muscles, and von Lindern et al. was the only study to inject patients in all muscles of mastication based on the area of tenderness (42). Both Altaweel et al. (37) and Yoshida et al. (43) exclusively injected their patients in the lateral pterygoid muscle. Batifol et al. (38) was the only included study to inject patients in the intra-articular area with no mention of which muscles.

Target muscle identification and confirmation was done by palpitation in two studies $(38,44)$, palpitation after topography in one study (42), and palpitation guided ultrasonography in a further single study (48), while the remaining seven $(22,37,39-41,43,45)$ studies used electromyography for confirmation of the target muscle. A standardized dose of BTX injections has not yet been established. Although the doses used are decisive when treating TMDs, only the lowest effective dose should be administered to prevent the formation of antibodies from excess dosage that can lead to poisoning. In this examiniation of 11 studies, a variety of doses ranging between 50 to $300 \mathrm{U}$ were identified. Almost all studies injected patients bilaterally, except for Yoshida et al. (43) who injected patients according to the site of temporomandibular dislocation (either uni- or bilaterally). Patients were initially monitored for up to one month after the BTX injection in five studies (38-40, $42,48)$, while the other six $(22,37,41,43-45)$ reported longer follow-up periods.

The primary outcome identified was pain relief after BTX injection with a general tendency for pain to improve over time. Meanwhile, short-term enhancements were reported by Altaweel et al. (37), 
Batifol et al. (38), Sipahi Calis et al. (41), Kurtoglu et al. (39), von Lindern et al. (42), Yoshida et al. (43), GuardaNardini et al. (44), and Patel et al. (45). Conversely, Nixdorf et al. (40) and Ernberg et al.(22) indicated no significant improvement in pain intensity after the BTX administration for TMD patients. Ernberg et al. (22) also demonstrated minimal short-term and long-term enhancements.

Additional outcomes include changes in mouth opening and the presence of adverse outcomes following BTX injections. Significant improvement in mouth opening was observed by Altaweel et al. (37) and Batifol et al. (38). The two studies conducted by Guarda-Nardini et al. $(44,48)$ showed a slight improvement in mouth opening, but Ernberg et al. (22) demonstrated no significant improvement in mouth openness during the study or after the follow-up period. Furthermore, Nixdorf et al. (40) improvement was identified in the placebo group, unlike the BTX group who experienced opening reduction. Sipahi Calis et al. (41) reported that two of his patients experienced reduced mouth opening while six patients had increased mouth opening ability, and only one patient showed no change.

Therefore, the effect of BTX injections on mouth opening diameter can be considered to be minimal, as identified by the study authors. No novel adverse effects or complications were reported by any of the included studies. Adverse effects defined by four of the included studies included headaches, weakness, increased pain, flu-like symptoms, chewing discomfort and unilateral paralysis of the zygomatic us major muscle $(22,38,40$, 44). However, adverse effects caused by BTX local infusion may be dose dependant, and should be considered in future investigations $(50,51)$. It is worth mentioning that Altaweel et al. (37) assessed TMJ clicking and it was significantly reduced after BTX adminstration. Additionally, the authors reported persistant joint and laterl ptyregoid muscle tenderness despite having no marks on VAS.

Limitations within our study include the small sample size of the assessed patients in the final included studies. In addition, long-term follow-up periods should be defined and completed by each study as it may otherwise contibute to attrition bias. For example, Nixdorf et al. (40) results indicated improved mouth opening in the placebo group but a decreased ability in the BTX group. Variable follow-up periods have been used to assess the included patients. Moreover, unified diagnostic criteria was not utilized in all of the included studies. None of the included studies compared two different BTX formulations while further studies aimed at assessing formulations and doses are needed. Finally, the high costs of favoring BTX over other therapies should be also considered (47) even if BTX injection is injected once only with no requirements for daily routine compliance (52).

\section{Conclusion}

It is difficult to determine the effect of BTX on TMD patients due to several limitations characteristic of the included studies. It is therefore essential that more research is conducted in this field with proper populations and fewer limitations. However, we can conclude that the administration of BTX is almost free of severe complications and only causes minimal adverse effects.

\section{Acknowledgment}

None

\section{Disclosure}

\section{Statement:}

The authors declare no conflict of interest

\section{Funding}

None

\section{Ethical Consideration}

None applicable

\section{References}

1. Zakrzewska JM. Differential diagnosis of facial pain and guidelines for management. British journal of anaesthesia. 2013;111 (1):95-104.

2. Kanner R. Facial pain: After the dentist and ENT have finished. Neurol Clin Pract. 2012;2(3):172-8.

3. Dworkin SF, Huggins KH, LeResche L, Von Korff M, Howard J, Truelove E, et al. Epidemiology of signs and symptoms in temporomandibular disorders: clinical signs in cases and controls. Journal of the American Dental Association (1939). 1990;120 (3):273-81. 
Journal of Healthcare Sciences

4. Goulet JP, Lavigne GJ, Lund JP. Jaw pain prevalence among French-speaking Canadians in Québec and related symptoms of temporomandibular disorders. Journal of dental research. 1995;74(11):1738-44.

5. Dao TT, LeResche L. Gender differences in pain. Journal of orofacial pain. 2000;14 (3):169-84; discussion 84-95.

6. Macfarlane TV, Blinkhorn AS, Davies RM, Kincey J, Worthington HV. Oro-facial pain in the community: prevalence and associated impact. Community dentistry and oral epidemiology. 2002;30 (1):52-60.

7. Janal MN, Raphael KG, Nayak S, Klausner J. Prevalence of myofascial temporomandibular disorder in US community women. Journal of oral rehabilitation. 2008;35(11):801-9.

8. Al-Jundi MA, John MT, Setz JM, Szentpétery A, Kuss O. Meta-analysis of treatment need for temporomandibular disorders in adult nonpatients. Journal of orofacial pain. 2008;22(2).

9. Manfredini D, Guarda-Nardini L, Winocur E, Piccotti F, Ahlberg J, Lobbezoo F. Research diagnostic criteria for temporomandibular disorders: a systematic review of axis I epidemiologic findings. Oral Surgery, Oral Medicine, Oral Pathology, Oral Radiology, and Endodontology. 2011;112(4):453-62.

10. Herb K, Cho S, Stiles MA. Temporomandibular joint pain and dysfunction. Current Pain and Headache Reports. 2006;10 (6):408-14.

11. Kelleher M, Ray-Chaudhuri A, Khawaja N. Patients' Priorities and Attitudes Towards Their Temporo-Mandibular Disorders. Primary dental journal. 2015;4 (3):17-21.

12. Huang GJ, LeResche L, Critchlow CW, Martin MD, Drangsholt MT. Risk factors for diagnostic subgroups of painful temporomandibular disorders (TMD). Journal of dental research. 2002;81 (4):284-8.

13. Macfarlane TV, Gray RJM, Kincey J, Worthington HV. Factors associated with the temporomandibular disorder, pain dysfunction syndrome (PDS): Manchester case-control study. Oral diseases. 2001;7(6):321-30.

14. Velly AM, Gornitsky M, Philippe P. Contributing factors to chronic myofascial pain: a case-control study. Pain. 2003;104(3):491-9.

15. Guarda-Nardini L, Manfredini D, Salamone M, Salmaso L, Tonello S, Ferronato G. Efficacy of Botulinum Toxin in Treating Myofascial Pain in Bruxers: A Controlled Placebo Pilot Study. CRANIO®. 2008; 26 (2):126-35.

16. Lyons MF. Current practice in the management of temporomandibular disorders. Dental update. 2008;35(5):314-6, 8.

17. Schiffman E, Ohrbach R, Truelove E, Look J, Anderson G, Goulet JP, et al. Diagnostic Criteria for Temporomandibular Disorders (DC/TMD) for Clinical and Research Applications: recommendations of the International RDC/TMD Consortium Network* and Orofacial Pain Special Interest Group $†$. Journal of oral \& facial pain and headache. 2014;28 (1):6-27.

18. Kuttila S, Kuttila M, Bell Y, Alanen P, Suonpää J. Characteristics of subjects with secondary otalgia. Journal of orofacial pain. 2004;18:226-34.

19. Petscavage-Thomas JM, Walker EA. Unlocking the Jaw: Advanced Imaging of the Temporomandibular Joint. American Journal of Roentgenology. 2014;203(5):1047-58.

20. List T, Axelsson S, Leijon G. Pharmacologic interventions in the treatment of temporomandibular disorders, atypical facial pain, and burning mouth syndrome. A qualitative systematic review. Journal of orofacial pain. 2003;17(4):301-10.

21. Dworkin SF, Turner JA, Mancl L, Wilson L, Massoth D, Huggins KH, et al. A randomized clinical trial of a tailored comprehensive care treatment program for temporomandibular disorders. Journal of orofacial pain. 2002;16 (4):259-76.

22. Ernberg M, Hedenberg-Magnusson B, List T, Svensson P. Efficacy of botulinum toxin type A for treatment of persistent myofascial TMD pain: 
A randomized, controlled, double-blind multicenter study. Pain. 2011;152 (9):1988-96.

23. Chen YW, Chiu YW, Chen CY, Chuang SK. Botulinum toxin therapy for temporomandibular joint disorders: a systematic review of randomized controlled trials. International Journal of Oral and Maxillofacial Surgery. 2015;44 (8):1018-26.

24. Naumann M, So Y, Argoff CE, Childers MK, Dykstra DD, Gronseth GS, et al. Assessment: Botulinum neurotoxin in the treatment of autonomic disorders and pain (an evidence-based review): report of the Therapeutics and Technology Assessment Subcommittee of the American Academy of Neurology. Neurology. 2008;70(19):1707-14.

25. Gadhia K, Walmsley AD. Facial aesthetics: is botulinum toxin treatment effective and safe? A systematic review of randomised controlled trials. British dental journal. 2009;207 (5):E9; discussion 216-7.

26. Sellin LC, Thesleff S. Pre- and post-synaptic actions of botulinum toxin at the rat neuromuscular junction. J Physiol. 1981;317:48795.

27. Aoki KR. Review of a proposed mechanism for the antinociceptive action of botulinum toxin type A. Neurotoxicology. 2005;26(5):785-93.

28. Purkiss J, Welch M, Doward S, Foster K. Capsaicin-stimulated release of substance $\mathrm{P}$ from cultured dorsal root ganglion neurons: involvement of two distinct mechanisms. Biochemical pharmacology. 2000;59 (11):1403-6.

29. Liberati A, Altman DG, Tetzlaff J, Mulrow C, Gøtzsche PC, Ioannidis JP, et al. The PRISMA statement for reporting systematic reviews and meta-analyses of studies that evaluate health care interventions: explanation and elaboration. PLoS medicine.2009;6(7):e1000100.

30. Vassar M, Atakpo P, Kash MJ. Manual search approaches used by systematic reviewers in dermatology. Journal of the Medical Library Association: JMLA. 2016;104(4):302.
31. Health NIo. Quality assessment tool for observational cohort and cross-sectional studies. National Heart, Lung, and Blood Institute Avaliable from: www nhlbi nih gov/healthpro/guidelines/indevelop/cardiovascular-riskreduction/tools/cohort[Accessed November 5, $2015] 2014$.

32. Leung A, Heal C, Perera M, Pretorius C. A systematic review of patient-related risk factors for catheter-related thrombosis. Journal of thrombosis and thrombolysis. 2015;40(3):363-73.

33. Mor N, Tang C, Blitzer A. Temporomandibular myofacial pain treated with botulinum toxin injection. Toxins. 2015;7(8):2791-800.

34. Bhogal PS, Hutton A, Monaghan A. A Review of the Current Uses of Botox for Dentally-Related Procedures. Dental update. 2006;33(3):165-8.

35. Schwartz M, Freund B. Treatment of temporomandibular disorders with botulinum toxin. The Clinical journal of pain. 2002;18 (6 Suppl):S198-203.

36. Gassner HG, Sherris DA. Addition of an Anesthetic Agent to Enhance the Predictability of the Effects of Botulinum Toxin Type A Injections: A Randomized Controlled Study. Mayo Clinic Proceedings. 2000;75 (7):701-4.

37. Altaweel AA, Elsayed SA, Baiomy A, Abdelsadek SE, Hyder AA. Extraoral Versus Intraoral Botulinum Toxin Type A Injection for Management of Temporomandibular Joint Disc Displacement With Reduction. The Journal of craniofacial surgery. 2019;30 (7):2149-53.

38. Batifol D, Huart A, Finiels PJ, Nagot N, Jammet P. Effect of intra-articular Botulinum toxin injections on temporo-mandibular joint pain. Journal of Stomatology, Oral and Maxillofacial Surgery. 2018;119(4):319-24.

39. Kurtoglu C, Gur OH, Kurkcu M, Sertdemir Y, Guler-Uysal F, Uysal H. Effect of botulinum toxin-A in myofascial pain patients with or without functional disc displacement. Journal of 
oral and maxillofacial surgery: official journal of the American Association of Oral and Maxillofacial Surgeons. 2008;66 (8):1644-51.

40. Nixdorf DR, Heo G, Major PW. Randomized controlled trial of botulinum toxin A for chronic myogenous orofacial pain. Pain. 2002;99(3):46573.

41. Sipahi Calis A, Colakoglu Z, Gunbay S. The use of botulinum toxin-a in the treatment of muscular temporomandibular joint disorders. Journal of stomatology, oral and maxillofacial surgery. 2019;120(4):322-5.

42. Von Lindern JJ, Niederhagen B, Bergé S, Appel T. Type A botulinum toxin in the treatment of chronic facial pain associated with masticatory hyperactivity. Journal of oral and maxillofacial surgery: official journal of the American Association of Oral and Maxillofacial Surgeons. 2003;61(7):774-8.

43. Yoshida K. Botulinum Neurotoxin Injection for the Treatment of Recurrent Temporomandibular Joint Dislocation with and without Neurogenic Muscular Hyperactivity. Toxins. 2018;10(5).

44. Guarda-Nardini L, Stecco A, Stecco C, Masiero S, Manfredini D. Myofascial pain of the jaw muscles: comparison of short-term effectiveness of botulinum toxin injections and fascial manipulation technique. Cranio : the journal of craniomandibular practice. 2012;30(2):95-102.

45. Patel AA, Lerner MZ, Blitzer A. IncobotulinumtoxinA Injection for Temporomandibular Joint Disorder. The Annals of otology, rhinology, and laryngology. 2017;126(4):328-33.
46. Chen JJ, Dashtipour K. Abo-, Inco-, Ona-, and Rima-Botulinum Toxins in Clinical Therapy: A Primer. Pharmacotherapy: The Journal of Human Pharmacology and Drug Therapy. 2013;33(3):30418.

47. Thambar S, Kulkarni S, Armstrong S, Nikolarakos D. Botulinum toxin in the management of temporomandibular disorders: a systematic review. The British journal of oral $\&$ maxillofacial surgery. 2020;58 (5):508-19.

48. Guarda-Nardini L, Manfredini D, Salamone M, Salmaso L, Tonello S, Ferronato G. Efficacy of botulinum toxin in treating myofascial pain in bruxers: a controlled placebo pilot study. Cranio: the journal of craniomandibular practice. 2008;26(2):126-35.

49. Conti PC, de Azevedo LR, de Souza NV, Ferreira FV. Pain measurement in TMD patients: evaluation of precision and sensitivity of different scales. Journal of oral rehabilitation. 2001;28(6):534-9.

50. Pearce LB, Borodic GE, Johnson EA, First ER, Maccallum R. The median paralysis unit: A more pharmacologically relevant unit of biologic activity for botulinum toxin. Toxicon. 1995;33(2):217-27.

51. Shaari CM, Sanders I. Quantifying how location and dose of botulinum toxin injections affect muscle paralysis. Muscle \& Nerve. 1993;16(9):964-9.

52. Patel J, Cardoso JA, Mehta S. A systematic review of botulinum toxin in the management of patients with temporomandibular disorders and bruxism. British dental journal. 2019;226 (9):667-72. 